\title{
Correction to: Spatial attention impairments are characterized by specific electroencephalographic correlates and partially mediate the association between early life stress and anxiety
}

Arielle S. Keller ${ }^{1,2} \cdot$ Ruth Ling $^{2} \cdot$ Leanne M. Williams $s^{2,3}$

Published online: 20 December 2021

(C) The Psychonomic Society, Inc. 2021

Correction to: Cognitive, Afective, \& Behavioral Neuroscience https://doi.org/10.3758/s13415-021-00963-0

This article was updated to correct errors in Fig. 3 introduced during the production process.

Publisher's note Springer Nature remains neutral with regard to jurisdictional claims in published maps and institutional affiliations.

The online version of the original article can be found at https:// doi.org/10.3758/s13415-021-00963-0

Leanne M. Williams

leawilliams@stanford.edu

1 Graduate Program in Neurosciences, Stanford University, Stanford, CA, USA

2 Department of Psychiatry and Behavioral Sciences, Stanford University, 401 Quarry Road, Stanford, CA 94134, USA

3 MIRECC, VA Palo Alto Health Care System, Palo Alto, CA, USA 